\title{
Learning from the National Manufacturing Industrial System
}

\author{
Michele Lo $\operatorname{Re}^{1}$, Eleonora Veglianti ${ }^{2}$, Fabrizio Parente ${ }^{3}$ \\ ${ }^{1}$ Department of Economics and Management, LUISS Guido Carli University and GRIF “Industrial and Financial Research Center”, Roma, \\ Italy \\ ${ }^{2}$ Department of Economics, Uninettuno University, Rome, Italy \\ ${ }^{3}$ Department of Anatomy, Histology Forensic Medicine and Orthopaedics Sapienza University of Rome, Roma, Italy
}

Email address:

mlore@luiss.it (M. Lo Re)

\section{To cite this article:}

Michele Lo Re, Eleonora Veglianti, Fabrizio Parente. Learning from the National Manufacturing Industrial System. International Journal of Industrial and Manufacturing Systems Engineering. Vol. 5, No. 4, 2020, pp. 46-54. doi: 10.11648/j.ijimse.20200504.12

Received: December 1, 2020; Accepted: December 9, 2020; Published: December 31, 2020

\begin{abstract}
The recent wave of rising protectionism and re-internationalization of capital poses a significant challenge to national industrial system that structures the network and governance firms. This work aims to analyze the global commercial network of the Italian manufacturing industry under the lenses of the network analysis, describing its peculiarities and the development and internationalization paths of its international branches. The originality of the work is also that improving the ability to analyze and manage information extracted from unstructured data (stemming from notes to the firm financial statements). An adjacency matrix created on BvD-Orbis (Bureau van Dijk Electronic Publishing) flagship company database. It contains information about over 12.000 large Italian companies and belonging to one or more of 17.000 different branches in 2017. In this way it was possible to understand the evolving dynamics of the sales network of the Italian branches. The results confirm that the manufacturing industry represents a significant challenge for the design of industrial policy for the national industrial system, highlighting that the structural changes in global production have aroused renewed interest in the role of this sector in promoting economic development and policy. Following this perspective, we demonstrate the relationship between the network of countries shared by Italian companies and we highlight the fundamental characteristics in the structure of intersectoral connections.
\end{abstract}

Keywords: Manufacturing, Intersectoral Linkages, Network Analysis, Italy, Industrial Policy

\section{Introduction}

In a complex world tending to a new multipolarity, we are witnessing a colossal redistribution of power and economic prestige at international level, with a firm spatial reconfiguration of the global manufacturing industrial system [1]. Under this aspect, the structural changes in global manufacturing and the economic crisis have raised renewed interest in the role of the manufacturing sector in driving economic development [2].

This paper explores international trade of the Italian manufacturing industries through the lenses of Network Analysis, to visualize the world trade network of the Italian economy and describe its topology, in this context. In fact, we are attending on a new era of economic policy of restraining trade between states (countries), and of protectionism.

The slow de-structuring of the political and commercial categories consolidated during the twentieth-century globality has opposed the pervasiveness of the interpretive systems of the international system, with attempts to "repolarize the world", implemented with economiccommercial levers.

\subsection{Global Trade Networks and National Industrial Systems}

In this sense, the recent wave of rising protectionism and re-internationalization of capital poses a significant challenge to national industrial system that structures the network and governance of large firms [3]. According to proponents, these policies can counteract unfair trade practices, to allow fair competition between imports, goods and services produced domestically.

This new internationalization process of national firms reflects the global economic forces, i.e. the mobility of capital, 
trends in trade and direct investments, legislator votes, with effects on: the business cycle instrument, the dynamic operation of legal regulation (as a potential protectionist tool for governments) and the growing tension between globalization and protectionism. In this scenario, the manufacturing sector also exhibits stronger intersectoral backward and forward linkage effects, as well as, spillover effects.

At the same time, recently, the processes of geographical relocation of manufacturing production have developed. It is difficult to map precisely the outlines of this phenomenon, given the absence of official statistical sources, but it is certainly useful to understand the links between country of origin, qualified personnel and companies abroad. Moreover, it may have significant strategic-economic effects.

We investigate about the following issue: how may will change the world trade network of the Italian manufacturing firms in a protectionism context in the medium/long term?

To achieve this, studying and understanding system relations within a community or a specific territory, as well as, understanding the role of the world trade network of Italian manufacturing industries is crucial. Moreover, this specifies what is the role of the different countries where firms operate.

The global trade network has been performed taking into consideration that the network system is composed by many highly interconnected dynamical units [4]. To capture the global properties of such system, it is important to model them as a graph whose nodes represent the dynamical units and whose links stand for interaction between them.

The main advantage in using network analysis to explore international links of Italian firms relies on the piece of information that networks provide. The graph represents a strategic industrial network taking into account the relation between the Italian companies in the world aggregated for a sectoral view, where nodes are countries and links are firms that have common branches in the same region.

\subsection{Main Topic and Work Breakdown Structure}

In this way, we achieved the structure and dynamics of this complex networks, summarizing the relevant consideration of economic policy.

Moreover, the world trade network of Italian manufacturing industries and global centrality measures are useful for a comprehensive study of Italian economic context and for a better understanding on which countries are relevant nowadays and in the future.

The study is organized as follows. After introduction, section 2 presents a literature review on the relevant scientific contributions. Section 3 is about the model of network structure. After, the literature review, we describe some of the common properties observed in the topology of real-world trade network of Italian manufacturing industries and how they are measured.

Section 4 describes our data and measures and sets out the methodological and conceptual framework of the network theory and other approaches used in this work. Sections 5 is followed by scientific discussion of the empirical results.
Section 6, in the end, explains concluding remarks and reasons for reported phenomenon in results and discussion section.

\section{Literature Review}

Openness to international trade remains one of the most hotly debated topics in economics [5]. Apart from the distributional consequences, one of the main concerns is the potential vulnerability to foreign business cycle shocks that trade liberalization brings along [6]. International trade has been growing no faster than world GDP since the end of the recent global financial crisis. Thus, it is no longer an "engine of growth" as it was before the crisis [7].

One major reason for this has been the increase in trade protection during the last decade, as advanced nations tried to shelter their industries suffering from heavy job losses attributed to excessive trade deficits. We now know, however, that more than 80 percent of manufacturing job losses in developed countries, during the past two decades, has been due to the introduction of new "disruptive" technologies and innovations, rather than from trade.

\subsection{Firm as Network}

A bunch of scholars, mostly in the network field developed and discussed a variety of measures for centrality, prestige, power and status in social systems and tools.

Following the evolutionary theory of the firm, scholars state that knowledge exists in social relations among cooperating members of a community without fixed boundaries. We consider a firm as a network of differentiated roles and responsibilities in which the access to internal and external knowledge networks enables it to continuously create and renew its competitive advantage. The first stream of research in internationalization of firms focus about the international exploitation of firms, especially multinational companies, competitive advantage which involve leveraging the local-home knowledge from the headquarters to the subsidiary [8].

In a globalized economy, knowledge wide spreads and the firm's advantages does not derive only from home-based competences but from the range of locations where subsidiaries are established while interacting. The interest in knowledge flows has increased among academics especially, knowledge transfers from more to less developed countries and in highly specialized industry clusters $[9,10]$.

From a network perspective, the so-called integrated players have the most valuable knowledge resources with inflows and outflows of knowledge. They represent 'knowledge brokers' or 'regional innovation relays' that span structural holes between local entity and global headquarters.

The modern network theory evolved by the classical graph theory, developed by Leonhard Euler, to solve the Konigsberg bridge problem. Through the past century this mathematical theory improved such to become an analytical approach capable to quantify general as well as local patterns of data series. In such an approach, a phenomenon is translated in a network, adapted to a specific problem, and the results can be 
interpreted in that peculiar context.

\subsection{The Network Analysis}

As a general point of view, a network is described by a series of objects called nodes and some relations among them known as links. The network obtained can be described by a square matrix, the Adjacency Matrix (AM), where the $i, j$ location indicates the existence of a link between $i$ and $j$ nodes.

The nature of such relation can be described in different ways: in the first model, we use a topological approach such that nodes have only two possibilities: have a link (1), or not (0), thus, we study a binary network. The latter is useful when there is not specific metric to describe the relations between nodes. As an alternative model, we can associate a weight for each link. In this case, the connections have a specific meaning and can be useful to insert in the analysis, for example, a spatial network where the nodes have a specific position in a map and weights are the distance between them.

Moreover, with both these models a link can be characterized by a direction (directed network), indicating a preferential way for the flow of information through nodes (i.e. one-way traffic system).

Using these approaches, it is possible to study the whole system and to clarify its characteristics. An increasing focus is on the study of complex network: in such a model, the networks have an irregular and complex structure and can evolve dynamically in time with systems with thousands (or more) of nodes. In this field, reference [11] developed the small-world networks describing a network with characteristics of both regular and random network. This allows to speed up the communication among distant nodes, thanks to a relatively small number of shortcuts.

Another classical model is the scale-free networks [12]. In this case, there is an inhomogeneous distribution of nodes characterized by the simultaneous presence of a few central nodes (most connected) and many poorly connected nodes. This structure stabilizes the system from a failure, decreasing the probability to remove a central nodes (hub) chosen randomly. This analytical method is very flexible and was used to study many different systems from the biological to the social system [13]. Some Authors are considering complex networks' resilience against attacks represents a crucial issue in terms of network structure integrity.

\subsection{Our Approach and the Analysis Objectives}

In this work, we propose an application of such approach in economics to study the networks of abroad Italian manufacturing companies.

In this respect, the analysis aims at enhancing the capabilities of asset management at our disposal, extracted from unstructured data information useful to understand the evolving dynamics of the commercial network of Italian branches. Through a path of research, consultation, processing and standardization of information, it has been possible to define the representative model of Italian manufacturing companies in various sectors of the globe, dividing them into three clusters each with its own peculiarities.

\section{The Model: Italian Manufacturing Industries Network in the World}

Networks are complex systems whose individual elements interact, and thus cannot be viewed in isolation. An aspect not particularly examined in depth is the usage of Network Analysis as research method, but rather as an instrument aimed at monitoring ongoing development and evolution of the interactions between economic actors, within a reference system [14].

\subsection{Economic Network Model in Our Perspective}

The economic networks can be represented in three ways that are equivalent to one another in terms of informative content: a) sociograms - diagrams representing the individuals through points and the connections through lines connecting those points; b) graphs, and c) matrixes or sociometrics.

For the analysis of network economic problems based on a disaggregated examination of the value chains in network sectors, the following classification of complementary network levels is useful:

Level 1: network services (e.g. air transport, telecommunications services, generation and retail of electricity);

Level 2: infrastructure management (e.g. air traffic control, railway traffic control);

Level 3: network infrastructures (e.g. railway tracks, airports, telecommunications networks);

Level 4: public resources, on the basis of which network infrastructures and infrastructure management can be built (e.g. land, air, space, water).

This classification system differentiates between the markets for network services (Level 1), the markets for infrastructure management and network infrastructure capacities (Levels 2 and 3), and the upstream markets for public resources (Level 4). The significance of the economic characteristics of networks can vary substantially between network levels.

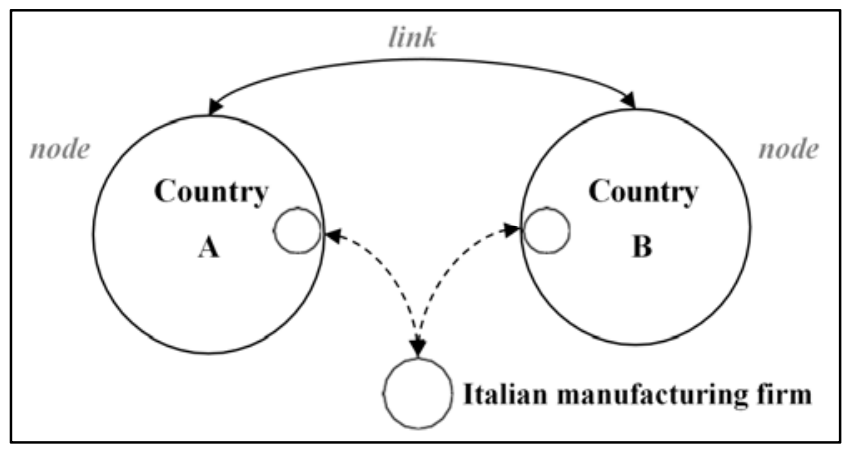

Figure 1. Own elaboration. Authors'network model.

In this paper, we tried to enlarge the perspective considering also geographic level towards a network approach (Figure 1). Through the study of the structure, the acquired abilities and 
the intent of each node, it is possible to understand how that network evolves in time and space.

This model demonstrates the relation perspective between the countries' network shared by the Italian companies. This means that there is a link if the same Italian company has a branch in two countries.

\subsection{Methods}

\subsubsection{Data and Network Settings}

An adjacency matrix created on BvD-Orbis (Bureau van Dijk Electronic Publishing) flagship company database. It contains information about over 12.000 large Italian companies and belonging to one or more of 17.000 different branches in 2017. This tool is specialized in company profile and financial statement data, although it sometime provides additional data on other closely related items, such as: market prices, analysts' forecasts or corporate governance indicators.

Many researchers consider this the major source for companies accounting and financial information across the world. The number of items available - the level of disaggregation of accounting data for Italian firms - is larger than in other databases. Besides, it adds value to this information because it standardizes the data and links together (Figure 2).



Figure 2. Own elaboration. Graph of the Italian manufacturing industries network in the world.

The analysis took into consideration 8292 companies (very large size Italian manufacturing companies with subsidiaries in the world with NACE Rev.2 main sections: CManufacturing) and 146 countries. Using this data, we created a weighted adjacency matrix defining the countries as nodes; while, the links and their weight as:

1) a link between two countries exist if the same company has a branch in both that given countries.

2) the weight of a link is the number of different companies having the branches in both that given countries.

In such a way, we have a matrix showing the network of countries shared by Italian companies. Each of the following analyses are based on this matrix.

\subsubsection{Network and Statistical Analysis}

The obtained matrix describes a weighted graph $\mathrm{GW}=(\mathrm{N}, \mathrm{L}$, W) consisting of a set of nodes $(\mathrm{N}=146)$ and a set of links ( $\mathrm{L}$ $=10.408)$ associated with set of weights $(\mathrm{W})$. To study the characteristics of this network, we started with a preliminary investigation. Further, we proceeded with a second part composed by a three steps analysis: the global and local features as well as the modularity architecture.

In the preliminary phase, we studied the dependence between the weight and the topology. In such a way, we calculated the strength (si) - the algebraical sum of the weights (w) of the node i- and the node degree (ki) - the algebraical sum of the links of the node $i$. Then, in presence of independence between these two values, the strength of the nodes as a function of degree $\mathrm{k}$ is a flat curve with the constant on the weights average: $\mathrm{s}(\mathrm{k})=\mathrm{k} *$ wmean (wmean= average of weights). Afterwards, we studied the distribution of weights among link of nodes (i.e. if the weights are equally distributed among the links, or there are few links containing the most past of the weight) using the disparity (Y).

In the second phase, we start exploring the global features of the network. Therefore, we calculated the strength distribution (Rs) among the nodes. The strength distribution measures the probability that a node has strength, providing a general information about the structure of a weighted network. In other words, we focused on the hypothesis that this distribution can be described by a heavy-tailed distribution in the form of power-law distribution. We computed the fitting of the distribution using the method of Reference [12]. Afterwards, we determined a set of general indices: Global and Local Efficiency and Assortativity.

The first two indices measure the efficiency of exchanges information among nodes: in the global scale, it indicates the information exchange across the whole network. While, in the local scale, it identifies how well information is exchanged by a node and its neighbors.

To characterize the non-random structure of the network, we compared the efficiency indices calculated in the real network to the same values calculated in 100 random models (see below for details). The last index: assortativity, describes the preference of nodes to have a connection with others that have similar strength.

On one side, if the value is positive the links with the larger weights are pointing to the neighbors with larger strength. On the other side, if the value is negative and if the value tends to be 0 , there is no preferential attachment among nodes.

Then, we focused on the local properties of the network that were characterized by three different centrality measures: strength, betweenness and eigenvector centrality. Strength, previously introduced, indicates the nodes that have the most shared branch with the other nodes and, indirectly, also the nodes with the larger number of branches of Italian companies. Betweenness centrality is a measure of centrality based on shortest paths (i.e. the path is a way between two nodes without passing through the same node).

Specifically, for a weighted network, the shortest path is the number of links that minimize the sum of the reciprocal weights of the links connecting two nodes. Hence, the central nodes with this measure is that nodes in which there is the larger number of paths connecting the whole network, 
indicating nodes that potentially can disconnect the network if removed. While, the eigenvector centrality characterized the node linked to another important node. In such a way, the node's centrality is the sum of the centrality values of the nodes that it is connected to. This indicates the centrality of the node itself but even the importance of its neighbors.

In the last phase of the analysis, we studied the modularity of the network. Hence, we explored the possible nodes' clusterization in several modules to distinguish the countries based on the different companies' strategies function of geographical factors or of the specific opportunities offered by that countries. We used modularity algorithm that search for an optimal community subdivision of the network into non-overlapping groups of nodes.

The aim was to maximize the number of within-group weights and minimize the number of between-group weights, such a behavior is described by the indices maximized modularity $(\mathrm{Q})$. Since, the results vary from run to run due to a heuristic in the algorithm, we performed 100 repetitions of calculation and took the clusterization.

Finally, to quantify the goodness of clusterization of the results, we compared $\mathrm{Q}$ values of real network to a 100-randomization model. The random model of the network was performed preserving the degree and strength distributions. The set of scripts used to calculate the previously measurement is contained in the Brain Connectivity Toolbox in Matlab.

\section{Results}

\subsection{Preliminary Analysis}

The network of countries sharing Italian companies shows that most of nodes have a node degree in the range from 142 to 145 (35 nodes with 142; 10 with 143; 51 with 144 and 47 with $145)$, and only three nodes have a lower value $(\mathrm{UG}=98, \mathrm{NA}=$ $98, \mathrm{LV}=107)$. The study of the dependence between strength and node degree does not highlight a relation, while the disparity (Y) has a small dependence with the node degree: indicating an independence between the number of link and the weight of nodes as well as a relatively equal distribution of weights among nodes.

These results indicate a general independence between the network topology and the weights characterizing the relation among nodes. Furthermore, the clear small sparse nature of the binary network (the network is almost completely connected) does not give enough variability among nodes, this does not allow us to describe significant differences between them. Thus, in the following analysis we take into account only the analysis of the weighted network, in which is contained a large part of the variability of the data.

\subsection{Global Properties}

The network has a higher level of global efficiency and relatively lower values for local efficiency (see table 1).
Table 1. Measures of the whole network. Values characterizing global features of the network are inserted. Global and local efficiency resulted significantly different compare to the random model.

\begin{tabular}{ll}
\hline Measures & Values (SD) \\
\hline Local Efficiency & $0.59(0.20)$ \\
Global Efficiency & 0.74 \\
Assortativity & 0.01 \\
\hline
\end{tabular}
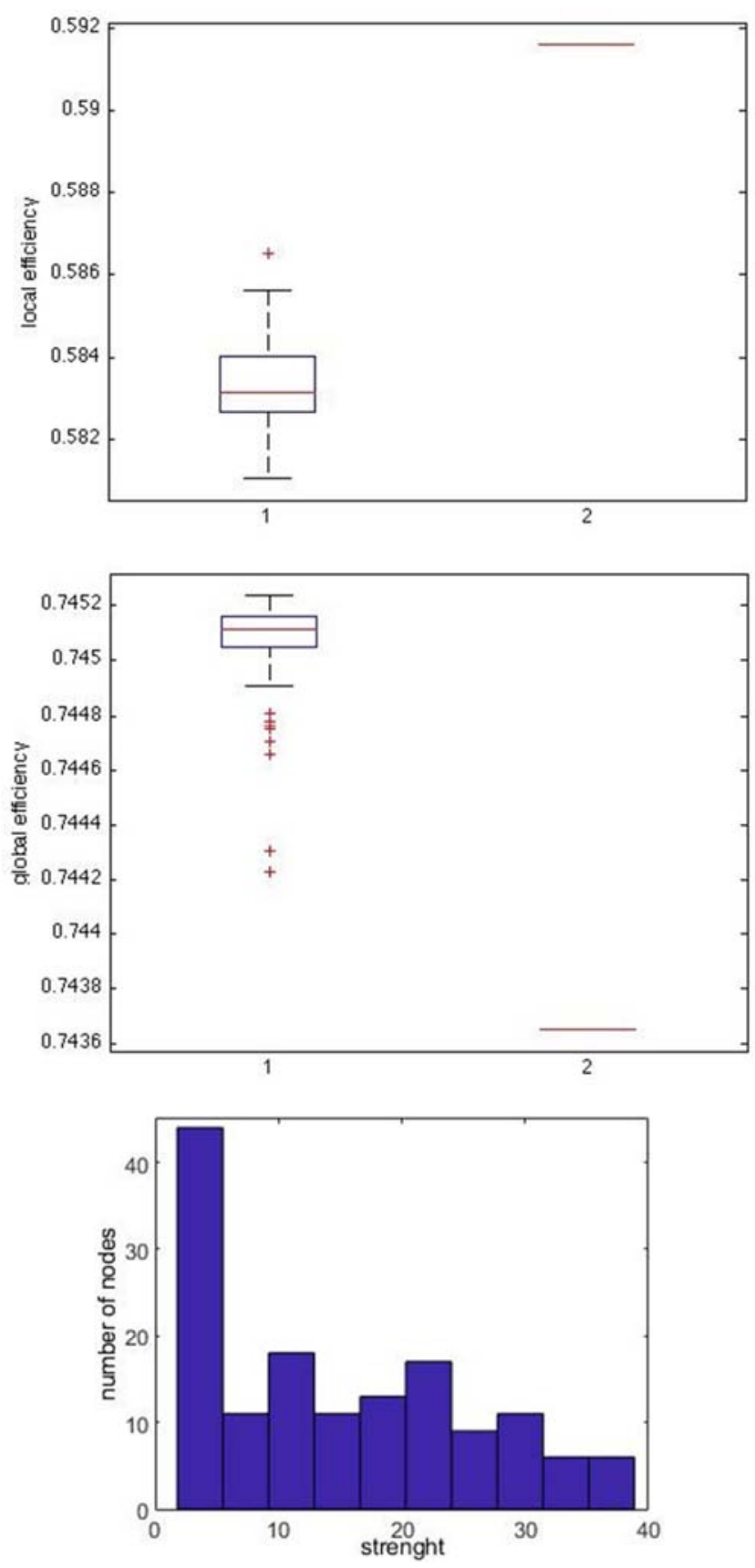

Figure 3. Strength distribution and Efficiency in comparison to the random model. In the upper panel the strength distribution is showed: most past of nodes falls in the lower level of strengths values, while the others are almost equi-distributed along the others strength values. In the bottom panel statistical analysis of local and global efficiency: in both cases real network show a significant results, indicating a higher local efficiency (corresponding to a well clusterized networks) and lower global efficiency (indicating a less efficient communication among nodes). Note that despite the small variability of random model the differences between the indexes are well characterized. $1=$ random networks, $2=$ original network. 
This means a good communication among the different nodes of the whole network, but not among the nodes within the sub-networks. Then, the comparison with random networks shows a small but significant difference in both the efficiency values (Figure 3). It is worth to note that a small standard deviation of random values can be ascribed to a non-efficient randomization process.

The assortativity tends to a zero value. This can denote a homogeneous distribution of weight among links, more than a random distribution. Finally, the strength distribution does not show a scale-free behavior ( $\mathrm{p}$-value $=0.37$ ) but has a large number of nodes having a lower level of strength, while the highest level of strength is contained in a small fraction of nodes (Figure 3 ).

The results obtained describe a network not represented by the traditional network models. However, the higher value of local efficiency seems indicate a clusterized feature, and a non-randomic structure it is not possible to exclude.

In the following modularity analysis, the network will be studied in detail in order to characterize the architecture.

\subsection{Local Properties}

Regarding the local properties, we used three different measures of centrality: strength, betweenness and eigenvector centrality. As a descriptive issue, it is evident a correlated trend among all the three centrality measures. Table 2 presents the central nodes for the different methods applied for the centrality analysis (the nodes indicated have a $\mathrm{z}$-score above the value of 1.96).

Table 2. Central nodes. Notice that the main countries for strength centrality are included in the other ones. Afghanistan appears as central nodes only in the betweenness centrality and France only in betweenness and eigenvector centrality.

\begin{tabular}{lll}
\hline Strength Country (codex): value & Betweenness Country (codex): value & Eigenvector Country (codex): value \\
\hline Bermuda (BM): 39,03 & Cyprus (CY): 1301 & France (FR): 0,18 \\
Cyprus (CY): 38,95 & Albania (AL): 1281 & Cyprus (CY): 0,18 \\
Albania (AL): 38,89 & France (FR): 1178 & Bermuda (BM): 0,18 \\
Armenia (AM): 37,00 & Bermuda (BM): 1089 & Albania (AL): 0,18 \\
& Armenia (AM): 668 & Armenia (AM): 0,17 \\
& Afghanistan (AF): 631 & \\
\hline
\end{tabular}

\subsection{Modularity}

The mean maximized modularity $(\mathrm{Q})$ presents a relatively low value with a low variability (0.06 S.D. $4 * 10-6)$, but significantly high compared with the random model (Figure 4).

There are not large differences among the different trials of the modularity algorithm, demonstrating a good agreement between them. Table 3 shows the most repeated pattern of clusterization obtained indicating three different clusters in which $\mathrm{A}$ and $\mathrm{B}$ have the larger number of nodes respect to $\mathrm{C}$.

The first cluster is the result in phases of the production process fragmentation whose geographical distribution depends on the ability to exploit cost gaps between productive factors, particularly raw materials. Internationalization in this case is not solely for the purpose of commercial penetration, but also for access to cost or expertise benefits.

The presence of Italian manufacturing companies in the countries belonging to this cluster often engages in privileged relationships with local actors outside the enterprise or find themselves managing the institutional differences between countries. In some cases, presence in these countries leads to the creation of exclusive competitive advantages linked to the availability of limited resources and intangible assets.

The second is the process of evolving companies abroad to look for new markets to serve or produce to sell their products and services in the markets of those countries.

This reasoning leads to identifying c.d. industry seeking investments related to the overseas market for productive purposes, which presupposes a linear growth model abroad and where the Italian company holds and develops key competencies. Typical subsidiaries of Cluster B perform executive functions by leveraging on the local markets the competitive superiority of the parent company.

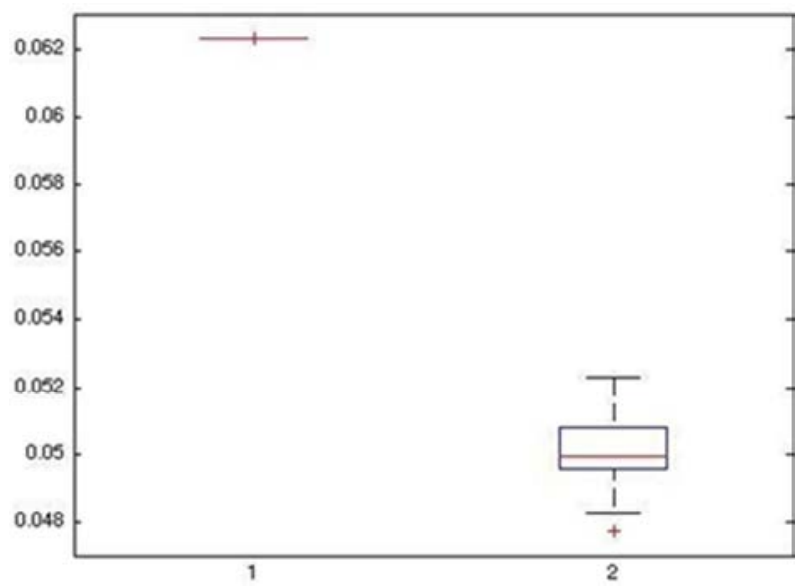

Figure 4. Comparison between the maximized modularity $(Q)$ of the real network (1), and random models (2). Real network shows a significant $Q$ index compared to the random model.

Table 3. Cluster of countries. A rationale parting of network nodes as a function of business services emerges from the analysis, indicating a possible trade-related agreement between countries.

\begin{tabular}{lll}
\hline Cluster A & Cluster B & Cluster C \\
\hline Azerbaijan (AZ) & Antigua and Barbuda (AG) & Abu Dhabi (AE) \\
Bolivia (BO) & Angola (AO) & Afghanistan (AF) \\
Republic of the Congo (CG) & Australia (AU) & Albania (AL) \\
Ivory Coast (CI) & Aruba (AW) & Armenia (AM) \\
Chile (CL) & Bosnia Herzegovina (BA) Bulgaria (BG) & Argentina (AR) \\
\hline
\end{tabular}




\begin{tabular}{|c|c|c|}
\hline Cluster A & Cluster B & Cluster C \\
\hline China $(\mathrm{CN})$ & Bahrain (BH) & Austria (AT) \\
\hline Germany (DE) & Belarus (BY) & Bangladesh (BD) \\
\hline Dominican Republic (DO) & Canada (CA) & Belgium (BE) \\
\hline Gibraltar (GI) & Central African Republic (CF) Cameroon (CM) & Bermuda (BM) \\
\hline Iraq (IQ) & Cuba (CU) & Brazil (BR) \\
\hline Japan (JP) & Czech Republic (CZ) & Botswana (BW) \\
\hline Liberia (LR) & Algeria (DZ) & Democratic Republic of Congo (CD) \\
\hline Lithuania (LT) & Ecuador (EC) & Switzerland $(\mathrm{CH})$ \\
\hline Macau (MO) & Estonia (EE) & Colombia (CO) \\
\hline Nicaragua (NI) & Egypt (EG) & Costa Rica (CR) \\
\hline Thailand (TH) & Spain (ES) & Cape Verde (CV) \\
\hline Uganda (UG) & Finland (FI) & Cyprus (CY) \\
\hline \multirow[t]{55}{*}{ Uzbekistan (UZ) } & Gambia (GM) & Denmark (DK) \\
\hline & Hong Kong (HK) & Eritrea (ER) \\
\hline & Croatia (HR) & Ethiopia (ET) \\
\hline & Hungary (HU) & France (FR) \\
\hline & Israel (IL) & Gabon (GA) \\
\hline & India (IN) & Equatorial Guinea (GB) \\
\hline & Iran (IR) & Georgia (GE) \\
\hline & South Korea (KR) & Ghana $(\mathrm{GH})$ \\
\hline & Kuwait (KW) & Guinea (GN) \\
\hline & Kazakhstan (KZ) & Greece (GR) \\
\hline & Lebanon (LB) & Guatemala (GT) \\
\hline & Liechtenstein (LI) & Guinea-Bissau (GW) \\
\hline & Libya (LY) & Honduras $(\mathrm{HN})$ \\
\hline & Morocco (MA) & Indonesia (ID) \\
\hline & Moldova (MD) & Ireland (IE) \\
\hline & Montenegro (ME) & Iceland (IS) \\
\hline & Macedonia (MK) & Jordan (JO) \\
\hline & Mongolia (MN) & Kyrgyzstan (KG) \\
\hline & Malta (MT) & Cambodia (KH) \\
\hline & Mexico (MX) & North Korea (KP) \\
\hline & Nigeria $(\mathrm{NG})$ & Kosovo (KV) \\
\hline & Nepal (NP) & Luxembourg (LU) \\
\hline & New Zealand (NZ) & Latvia (LV) \\
\hline & Oman (OM) & Monaco (MC) \\
\hline & Panama (PA) & Mauritania (MR) \\
\hline & Peru (PE) & Mauritius (MU) \\
\hline & Philippines (PH) & Malaysia (MY) \\
\hline & Pakistan (PK) & Mozambique (MZ) \\
\hline & Poland (PL) & Namibia (NA) \\
\hline & Portugal (PT) & Norway (NO) \\
\hline & Paraguay (PY) & Sudan (SD) \\
\hline & Qatar (QA) & Singapore (SG) \\
\hline & Romania (RO) & Slovakia (SK) \\
\hline & Russia (RU) & Togo (TG) \\
\hline & Saudi Arabia (SA) & Turkey (TR) British Virgin Islands (VG) Samoa (WS) \\
\hline & Sweden (SE) & \\
\hline & San Marino (SM) & \\
\hline & Senegal (SN) & \\
\hline & South Sudan (SS) & \\
\hline & Syria (SY) & \\
\hline & Swaziland (SZ) & \\
\hline & Turkmenistan (TM) & \\
\hline & Tunisia (TN) & \\
\hline & Trinidad and Tobago (TT) & \\
\hline & Taiwan (TW) & \\
\hline & Tanzania (TZ) & \\
\hline & Ukraine (UA) & \\
\hline & United States (US) & \\
\hline & Uruguay (UY) & \\
\hline & Venezuela (VE) & \\
\hline & Vietnam $(\mathrm{VN})$ & \\
\hline & Yemen (YE) & \\
\hline & South Africa (ZA) & \\
\hline & Zambia (ZM) & \\
\hline & Zimbabwe (ZW) & \\
\hline
\end{tabular}


The third cluster identified collects those countries with non-transferable benefits outlined by the presence of distinctive occupational skills in specific areas (such as land-embedded, such as financing sector) or foreign investment facilitations involved in particular taxation schemes deriving from aggressive government policies of attraction.

Each of these types of internationalization models has several sequential steps, each of which involves the acquisition of certain requirements that will allow the international market to be approached and to exploit the political and economic relations between the host country and the Country that intends to enhance the process of internationalization of its own companies.

The geography and distribution of branches or subsidiaries of Italian companies will follow the dynamics highlighted in the previous sections accompanied by a progressive regionalization of trade and investment. This is linked, firstly, to the emergence of new forms of international labor division and, on the other hand, to the rapid increase in regional and bilateral trade and investment treaties.

\subsection{General Remarks}

From the whole results of the analysis, the network seems does not have a structure properly described by the classic models of network theory (i.e. it does not describe like a small-world or scale-free network). Its strength distribution is characterized by few nodes having the higher values of weights and most of the nodes with lower values, indicating a similar feature of a "long tail" distribution. It is worth to underline that most Italian companies are shared by few countries.

Nevertheless, the overall efficiency features (local and global) show a different architecture compared to a random network with a more clusterized structure. This evidence was confirmed by the modularity analysis indicating that Italian companies are not arranged randomly between the countries.

Beyond the general network description, thanks to the processing and analysis of data in the adjacency matrix, it was possible to extract concrete information identifying the internationalization paths of Italian manufacturing companies around the world. Under this aspect, the main findings and the methodology used in this paper show the tendency of Italian companies to branch out in different countries, without specific forms of geographical concentration and aggregation between enterprises yet finding more attractive outlet countries for business and related countries.

These reasons lead to the conclusion that, although there is no structured rule of allocation of Italian firms abroad, there are trade-related agreements between different countries or that prospects for such relations will arise and for business agreements between countries (emergent phenomena among them).

\section{Discussion}

The changes caused by globalization, as well as the new multi-polar and reticular systems, have a strong influence on consolidated cognitive and interpretative flywheels, from which a strong resistance to change. From this point of view, crises are nothing more than a tool that forces change, to adapt the international system to new realities.

The structural changes in global manufacturing have raised renewed interest in the role of the manufacturing sector in driving economic development. Under this aspect the importance of internationalization for maintaining economic performance during the crisis and the growth prospects of businesses in this difficult cyclical phase also requires that the analysis be extended to more qualitative elements such as direct examination of business perceptions of Impediments that may affect their internationalization, and the evaluation of the strategies they have adopted or intend to adopt for the future.

Much has been written about networks trade in the scientific literature, however this paper is the first, to our knowledge, that describes Italian manufacturing industries network in the world demonstrating the relation perspective between the countries' network shared by the Italian companies. Other scientific works explain models regarding cross-sectional distribution of the number of foreign markets accessed by branches or cross-sectional geographic distribution of foreign contacts, and the dynamics of firm level exports.

It could be useful, in the mid-term, to analyze the sectors and workers most exposed to risks caused by the COVID-19 syndemic (not only pandemic).

The difficulty of building long-term scenarios will condition the strategic choices of Italian companies characterized by a series of fundamental dimensions for international coexistence:

i) the distribution of power and prestige, already invested by a colossal redistribution process of which it is impossible to predict the outcomes; ii) the organization of the international trade policy space on the one hand, by the shifting of the boundaries between the different regional areas, on the other hand, for a more inclusive tendency to the reversal of the relations between the global dynamics and the favor of the first.

Academy, intelligence scholars and industry professionals are beginning to grasp that in the bonds between the nodes of the networks, and therefore in those among human beings, lies a complex and fascinating truth, that the analysis, first, and the visual disciplines. Secondly, try to make this as a science. Understanding information is not always easy.

\section{Conclusion}

In this work, network thinking becomes an important in setting the complexity of large-scale phenomena. From the analysis it clearly emerges in which countries the Italian manufacturing companies are most present. Consequently, the structuring of Italian business policies does not seem to reflect a structured and coordinated dimension of the Country System. 
Rather, they seem to follow the "new cultural trajectories" of the economy having roots in a strong and overwhelming need for supra nationality, due to the need to create virtuous interdependencies between the various states and thus to gain in-depth knowledge of the links between industries in different countries [15].

In this context, the "Italian System" of manufacturing companies will increasingly have to face competitors who have behind them the support of their countries.

Industrial policy has now become indispensable, as an ordinary tool of economic policy. This is to capture all the potential of manufacturing as a growth headquarter of growth, not to leave the Italian industry with a handicap, especially in an ad high protectionist risk.

In the political and economic debate, the importance of protecting a country's commercial networks begins to become a priority for the development of the economic system itself, especially in times of negative economic times.

Moving on to the relationship between economic actors of the same network, the link is by no means taken for granted, hence the need to discuss and analyze in depth the links that join these concepts.

And even more in perspective, the need will inevitably favor the emergence of pivots taken individually in terms of companies, both geographically capable of opening new sectors and new specializations and reinterpreting in more technologically advanced terms than existing ones, as required by the international trends with which Italy must confront and with which it must be able to keep up.

These results suggested have important implications for practitioners and further scholarly research alike. Indeed, the importance of major trade agreements between countries can be assessed by at least two perspectives.

The first is that of the actual size and scope of the liberalization that they imply. This is reflected in access to and presence in international markets (e.g. bidding, new greenfield investment opportunities). The second perspective, further elaborated, highlights the global centrality of the agreements, in terms of geography, with regard to commercial, political and strategic routes. However, the catalyzing effect of these agreements on trade in goods and, in part, even in investments, it is possible to point out policy guidelines, inspired by drivers around which industrial policies have been drawn up in other major industrial countries. It is precisely these countries that will face the demand for tomorrow and promise the highest growth rates of sales.

\section{Acknowledgements}

We thank all the people who believed in this project and who, with loyal dedication, have helped us along this fantastic journey. We thank the people working in LUISS Guido Carli University and GRIF (Industrial and Financial Research
Center) for proving us the basic and applied research in the areas of industrial economics, competition, regulation, economics and corporate finance.

We also dedicate this work to Leonardo (born on February 26, 2020).

\section{References}

[1] Andreoni, A., Chang, H.-J., Industrial policy and the future of manufacturing. Economia E Politica Industriale, 43 (4), 491502, 2016.

[2] Pozzi C., L'Italia e i volti della globalizzazione: il ruolo della politica industriale, in l'Industria, 1, pp. 7-14, 2008.

[3] De Benedictis, L., Tajoli L., The World Trade Network, The World Economy, 34, 8, 1417-1454, 2011.

[4] Barigozzi M., Fagiolo G. Garlaschelli D., The Multi-Network of International Trade: A Commodity-Specific Analysis, Physical Review E, 81, 046104, 2010.

[5] Chaney T., The Network Structure of International Trade, NBER wp, 16753, 2011.

[6] Krugman, P., Protectionism and stimulus. New York Times Column from February, 2009.

[7] Monarca, U., Cassetta, E., Lo Re, M., Meleo, L., A Network Analysis of the Intersectoral Linkages Between Manufacturing and Other Industries in China and Italy, Global Journal of Emerging Market Economies, 2019, 11 (1-2), pp. 80-97.

[8] Mu, S.., Gnyawali, D. R. Hatfield, Foreign subsidiaries learning from local environments: An empirical test, Management International Review, Volume 47, Issue 1, pp 79$102,2007$.

[9] Porter, M. E., The Competitive Advantage of Nations, New York: Free Press, 1990.

[10] Cinelli M., Ferraro G., Iovanella A., Resilience of Core-Periphery Networks in the Case of Rich-Club, Complexity Volume, Article ID 6548362, 12, 2017.

[11] Watts, Duncan J.; Strogatz, Steven H., Collective dynamics of 'small-world' networks, Nature. 393 (6684): 440-442, 1998.

[12] Barabási, A. L.; Gulbahce, N.; Loscalzo, J., Network medicine: a network-based approach to human disease, Nature Reviews Genetics 12 (1): 56-68, 2011.

[13] Parente F, Frascarelli M, Mirigliani A, Di Fabio F, Biondi M, Colosimo A., Negative functional brain networks. Brain Imaging Behaviour Mar 29, 2017.

[14] Lo Re M., La Network Analysis: proposta di un framework concettuale per le applicazioni economiche, in L'industria (ISSN 0019-7416), Fascicolo 4, 2018.

[15] Clauset, C. R. Shalizi, Newman M. E. J., Power-law distributions in empirical data, SIAM Review, 51 (4), pp 661-703, 2009. 